\title{
Representações sociais sobre a velhice, o envelhecer e o ser velho segundo homens e
}

\section{mulheres idosos}

\author{
Social representations about old age, aging and being old according to elderly men and women \\ Representaciones sociales sobre la vejez, envejecimiento y ser viejo según hombres y mujeres
}

mayores

Recebido: 22/11/2021 | Revisado: 01/11/2021 | Aceito: 03/12/2021 | Publicado: 13/12/2021

\author{
Lúcia Vaz de Campos Moreira \\ ORCID: https://orcid.org/0000-0001-5102-9514 \\ Universidade Católica de Petrópolis, Brasil \\ E-mail: lucia.moreira@ucp.br \\ Julio Cesar Cruz Collares-da-Rocha \\ ORCID: https://orcid.org/0000-0003-1611-1920 \\ Universidade Católica de Petrópolis, Brasil \\ E-mail: juliorochapesquisa@gmail.com \\ Rafael Cerqueira Fornasier \\ ORCID: https://orcid.org/0000-0001-5982-6454 \\ Universidade Católica do Salvador, Brasil \\ E-mail: perafaelfornasier@gmail.com
}

\begin{abstract}
Resumo
Objetivo: Analisar as representações sociais sobre a velhice, o envelhecer e o ser velho segundo homens e mulheres idosos. Metodologia: Trata-se de uma pesquisa qualitativa, utilizando a Teoria das Representações Sociais de Serge Moscovici, junto a pessoas velhas residentes em bairro de classe média na Região Metropolitana de Salvador - Bahia - Brasil. Os dados foram coletados por meio de um roteiro de entrevista semiestruturado, com questões abertas formuladas pelos pesquisadores, que foram gravadas e transcritas integralmente e passaram por análise de conteúdo temática. Resultados: Os 60 participantes da pesquisa - 30 homens e 30 mulheres - apresentaram uma média de 73 anos e de 72 anos, respectivamente. Quanto às representações sociais investigadas, emergiram, principalmente, as seguintes categorias: a velhice como processo natural de vida; limitação física/cansaço; e questão subjetiva; o envelhecer como aceitar finitude com limites e mudanças; ter sabedoria/experiência; e tempo passar/viver bastante; e o ser velho como tempo de vida ter passado/ter mais limitações; ter experiência de vida/sabedoria; e acha que não tem que aprender ou fazer mais nada/perder otimismo. Conclusão do estudo: As representações sociais dos idosos pesquisados são diferentes quanto às principais categorias que destacamos, com conteúdos relacionados a conhecimentos/práticas sociais vinculados a desenvolvimento humano, limitações, passagem do tempo, sapiência e questões subjetivas. Compreendemos com os resultados que ser velho é um desafio para os participantes, em especial, tendo em vista as consequências negativas apontadas, ora naturalizadas, ora apresentadas como socialmente construídas e experienciadas no cotidiano nessa fase do desenvolvimento humano, tanto que, geralmente, não se reconhecem como velhos.
\end{abstract}

Palavras-chave: Envelhecimento; Pessoa idosa; Representações sociais; Análise de conteúdo; Desenvolvimento humano.

\begin{abstract}
Objective: To analyze the social representations of old age, aging and being old according to elderly men and women. Methodology: This is a qualitative research, using the Theory of Social Representations by Serge Moscovici, with elderly people living in a middle class neighborhood in the Metropolitan Region of Salvador - Bahia - Brazil. Data were collected through a semi-structured interview script, with open questions formulated by the researchers, which were recorded and transcribed in full and underwent thematic content analysis. Results: The 60 research participants 30 men and 30 women - had an average of 73 years and 72 years, respectively. As for the investigated social representations, the following categories emerged: old age as natural life process, physical limitation/tiredness and subjective issue; aging as accepting finitude with limits and changes, having wisdom/experience and time to spend/live a lot; and being old as time of life having passed/having more limitations, having experience of life/wisdom and thinks they don't have to learn or do anything else/lose optimism. Conclusion of the study: The social representations of the researched aged people are different regarding the main categories that we highlight, with contents related to social knowledge/practices linked to human development, limitations, the passage of time, wisdom and subjective issues. We understand from the results that being old is a challenge for the participants in view of the negative consequences pointed out, sometimes naturalized, sometimes presented as socially constructed and
\end{abstract}


experienced in everyday life at this stage of human development, so much so that, generally, they don't recognize themselves as old.

Keywords: Aging; Elderly person; Social representations; Content analysis; Human development.

\section{Resumen}

Objetivo: Analizar las representaciones sociales de la vejez, el envejecimiento y ser viejo según hombres y mujeres mayores. Metodología: Se trata de una investigación cualitativa, utilizando la Teoría de las Representaciones Sociales de Serge Moscovici, con personas mayores que viven en un barrio de clase media de la Región Metropolitana de Salvador - Bahía - Brasil. Los datos fueron recolectados a través de un guion de entrevista semiestructurado, con preguntas abiertas formuladas por los investigadores, las cuales fueron grabadas y transcritas íntegramente y sometidas a análisis de contenido temático. Resultados: Los 60 participantes de la investigación, 30 hombres y 30 mujeres, tenían un promedio de 73 años y 72 años, respectivamente. En cuanto a las representaciones sociales investigadas, surgieron las siguientes categorías: vejez como proceso de vida natural, limitación física / cansancio y cuestión subjetiva; envejecimiento como aceptar la finitud con límites y cambios, tener sabiduría / experiencia y tiempo para gastar / vivir mucho; y ser viejo como haber pasado un momento de la vida / tener más limitaciones, tener experiencia de vida / sabiduría y pensar que no tiene que aprender ni hacer nada más / perder optimismo. Conclusión del estudio: Las representaciones sociales de los ancianos investigados son diferentes en cuanto a las principales categorías que destacamos, con contenidos relacionados con saberes / prácticas sociales vinculadas al desarrollo humano, limitaciones, paso del tiempo, sabiduría y cuestiones subjetivas. Entendemos por los resultados que ser viejo es un desafío para los participantes, en particular, en vista de las consecuencias negativas señaladas, a veces naturalizadas, a veces presentadas como socialmente construidas y vividas en la vida cotidiana en esta etapa del desarrollo humano, tanto así que, en general, no se reconocen como viejos.

Palabras clave: Envejecimiento; Persona anciana; Representaciones sociales; Análisis de contenido; Desarrollo humano.

\section{Introdução}

As pessoas idosas no Brasil têm experimentado uma relevância não apenas social, tendo em vista o aumento da expectativa de vida da população e da participação social desse grupo, como científica, visto que os estudos sobre a velhice têm sido ampliados e captam aspectos variados da experiência nessa fase do desenvolvimento humano.

A ampliação da população idosa pressionou os governos, os pesquisadores e diversos profissionais a se atentarem a esse público, visando propiciar um envelhecimento ativo e bem-sucedido (Dias, 2013). Embora a temática do envelhecimento seja antiga na história da humanidade, já havendo referências a ela na China ancestral (Araújo \& Carvalho, 2005), o seu crescimento populacional a trouxe para o centro das atenções tanto internacional quanto nacionalmente. De acordo com a Pesquisa Nacional por Amostra de Domicílios - PNAD 2015, de 9,8\%, em 2005, a população brasileira de 60 anos ou mais de idade passou a corresponder a 14,3\%, ou seja, a 29,6 milhões (IBGE, 2016). Em 2050, a população de idosos deve triplicar, correspondendo a 29,3\% da população (Figueiredo, 2016). Além disto, haverá mais de 900 milhões de pessoas velhas no mundo. Deste modo, pessoas idosas, até recentemente de certo modo invisíveis, tornaram-se visíveis, não apenas em decorrência do seu crescimento numérico, como também devido à sua importância econômica em uma sociedade do consumo. Apesar disso, os velhos carecem de um maior reconhecimento social.

O Brasil estabelece a idade a partir de 60 anos como definindo o idoso - embora atualmente estabelecendo a idade de 80 anos como prioritária -, enquanto, nos países de primeiro mundo, esta idade seja de 65 anos em diante. Os idosos podem ser classificados como velhos-jovens, de 65 a 74 anos, velhos-velhos de 75 até 84 anos, e de muito-velhos, com 85 anos ou mais (Schaie \& Willis, 2000).

Tomé e Formiga (2020, p. 1) identificaram as principais teorias psicológicas relacionadas ao envelhecimento, subdividindo-as entre as clássicas ("Desenvolvimento ao Longo da Vida, Afastamento/desengajamento, Evolutiva e da Atividade, Continuidade e Fases do Desenvolvimento Psicológico ao Longo da Vida"), as de transição ("Desenvolvimento da Personalidade ao Longo da Vida e Teoria Social-interacionista da Personalidade na Velhice") e as contemporâneas ("Desenvolvimento ao Longo de Toda a Vida: life-span e life-course, Modelo de Desenvolvimento Bem-sucedido: otimização da seleção com compensação, Dependência Comportamental ou Aprendida, Seletividade Socioemocional, Controle no Curso 
de Vida e Eventos Críticos do Curso de Vida"). Estas demonstrariam não apenas a evolução sobre as representações do envelhecimento, mas também o contexto socio histórico de produção das mesmas, de modo que estas se complementam.

Acreditamos que a Teoria das Representações Sociais (TRS) de Serge Moscovici, criada para compreender a produção do senso comum no cotidiano (Moscovici, 2012), é adequada para identificar, segundo o conceito mais bem aceito na área, uma "forma de conhecimento, socialmente elaborada e partilhada, com um objetivo prático, e que contribui para a construção de uma realidade comum a um conjunto social" (Jodelet, 2001, p. 22), que nos propomos a investigar. Sobre a natureza das Representações Sociais, Sá (1996, p. 19) indicou que seria "tanto um conjunto de fenômenos quanto o conceito que os engloba e a teoria construída para explicá-los, definindo um vasto campo de estudos psicossociológicos”. Moscovici (2012) apontou que existem dois processos básicos vinculados às Representações Sociais, a ancoragem e a objetivação: o primeiro diz respeito à classificação de um determinado conhecimento e o segundo é o oferecimento de imagem para um conceito.

Pesquisas recentes, utilizando o referencial da Teoria das Representações Sociais, foram realizadas para compreender a questão do envelhecimento (Ferreira et al., 2017; Nascimento \& Calsa, 2017; Brito et al., 2018; Moura et al., 2019; Melo et al., 2020; Sardinha et al., 2020; Silva et al., 2020; Castro et al., 2020; Góis et al., 2020; Castro et al., 2021). Isso demonstra não apenas o interesse dos pesquisadores das representações sociais na temática do envelhecimento, como o valor da teoria para compreender as pessoas idosas em relação com o mundo que os cerca.

Visto isso, queremos responder com a presente investigação, qual conhecimento circula e é social produzido entre pessoas idosas de ambos os sexos sobre alguns aspectos relacionados à identidade social de ser idoso. Para tanto, o objetivo da pesquisa foi analisar as representações sociais sobre a velhice, o envelhecer e o ser velho segundo homens e mulheres idosos, a partir de dados coletados e categorizados como concepções e vivências.

\section{Metodologia}

Tratou-se de um estudo exploratório, de cunho qualitativo, descritivo, com amostra não probabilística por conveniência, utilizando o referencial da Teoria das Representações Sociais de Serge Moscovici (Moscovici, 2012), que permite conhecer quais são os conhecimentos de senso comum que são produzidos socialmente e estão em circulação entre grupos sociais.

A pesquisa faz parte de um estudo maior intitulado "Envelhecimento e velhice: pessoa, família, trabalho/aposentadoria, sociedade", que focalizou concepções e vivências de idosos sobre o envelhecimento e a velhice, numa perspectiva do desenvolvimento humano. Portanto, este artigo refere-se a uma reinterpretação das categorias encontradas, na investigação original, à luz da Teoria das Representações Sociais, pois identificamos que ela poderia ser útil na interpretação dos resultados obtidos.

Participaram da pesquisa 60 pessoas velhas residentes na Região Metropolitana de Salvador/Bahia/Brasil, sendo 30 homens e 30 mulheres. Os critérios de inclusão foram: ser idoso (ter 60 anos ou mais), residir em bairro de classe média da Região Metropolitana de Salvador/Bahia/Brasil e aceitar participar do estudo assinando o Termo de Consentimento Livre e Esclarecido (TCLE). É importante indicar que, apesar de termos entrevistado idosos de ambos os sexos, não foi nosso objetivo comparar suas representações sociais segundo sexo.

Como instrumento de pesquisa foi utilizado um roteiro de entrevista semiestruturado, com questões abertas, elaborado pelos pesquisadores e este aborda: dados de identificação; rotina; dados sobre família; amizades; trabalho/aposentadoria; atividades realizadas; pessoa; sociedade; sentido de vida e perspectivas futuras. Neste artigo serão apresentados somente os dados referentes aos itens dados de identificação e pessoa, que inclui questões relativas à velhice, ao envelhecer e ao ser velho - essas últimas permitiram respostas múltiplas. Em consonância com a Resolução no 466 de 12 de dezembro de 2012 sobre os 
aspectos éticos em pesquisa, o projeto foi submetido ao Comitê de Ética em Pesquisa da Universidade Católica do Salvador (UCSal) e aprovado (CAAE: 96934518.0.0000.5628). Após a aprovação, as entrevistas foram realizadas entre o segundo semestre de 2018 e o primeiro semestre de 2019.

Após o consentimento deles, foram realizadas as entrevistas com os idosos, em local de conveniência para eles, que duraram em média 60 minutos e foram gravadas para que nenhuma informação se perdesse. Caso houvesse desconforto, as entrevistas seriam interrompidas e os participantes seriam encaminhados a atendimento psicossocial, mas não houve necessidade.

As gravações das entrevistadas foram transcritas integralmente e depois analisadas. Foi feita análise de conteúdo temático-categorial (Oliveira, 2017), estabelecendo-se categorias a partir das falas coletadas e foi realizada análise descritiva, apresentando as porcentagens das respostas dos dados de identificação e da análise de conteúdo empreendida.

\section{Resultados e Discussão}

Quanto aos dados de identificação, as idades dos homens idosos variaram de 60 a 88 anos (média: 73 anos). Por sua vez, as idades das mulheres foram de 60 a 90 anos (média: 72 anos). Com relação à etnia, 47\% dos homens eram pardos, 43\% brancos e $10 \%$ negros. No que diz respeito às mulheres, $63 \%$ eram brancas, $23 \%$ pardas e $10 \%$ negras. Sobre o nível de escolaridade, $47 \%$ dos homens tinham ensino superior, 33\% ensino médio, $10 \%$ pós-graduação, $7 \%$ ensino fundamental e 3\% ensino técnico. Por outro lado, $43 \%$ das mulheres tinham nível superior, $27 \%$ ensino fundamental, $23 \%$ ensino médio e $7 \%$ pós-graduação. Quanto ao estado civil, $61 \%$ dos homens eram casados pela primeira vez, 13\% casados mais de uma vez, $13 \%$ divorciados, $7 \%$ solteiros, $3 \%$ estavam em união estável e 3\% eram viúvos. Por seu lado, 50\% das mulheres eram viúvas, 30\% casadas, $13 \%$ divorciadas e $7 \%$ solteiras. Sobre ocupação, $43 \%$ dos homens estão aposentados, $40 \%$ estão aposentados, mas continuam trabalhando, $13 \%$ estão trabalhando e $4 \%$ estão de licença médica (prestes a se aposentarem). Já 57\% das mulheres estavam aposentadas, 17\% trabalhavam, 13\% estavam aposentadas, mas continuavam trabalhando e 13\% nunca havia trabalhado de forma remunerada. Assim, constatamos, na população estudada, um bom nível de escolarização tanto dos homens quanto das mulheres, que há o predomínio de homens casados e de mulheres viúvas e de mais homens idosos trabalhando (mesmo que já estejam aposentados) do que de mulheres que, em sua maioria, estavam aposentadas.

Quanto às representações sociais sobre a velhice, o envelhecer e o ser velho segundo homens e mulheres idosos, apresentamos abaixo as tabelas, seguidas do elenco das principais categorias produzidas e a discussão das três principais categorias para cada um dos três objetos pesquisados (velhice, envelhecer e ser velho), levando em consideração a maior expressividade desses conteúdos representacionais nas percentagens totais. Os participantes foram identificados utilizando um código formado pelo sexo informado ( $\mathrm{M}$ - Masculino / F - Feminino), o número de identificação da pessoa entrevistada (01 60) e a idade dela. 
Tabela 1 - A velhice na perspectiva de idosos. Região Metropolitana de Salvador/Bahia, 2018 e 2019.

\begin{tabular}{|c|c|c|c|}
\hline A velhice segundo idosos* & $\begin{array}{l}\text { Percentagens de } \\
\text { velhos }(n=30)\end{array}$ & $\begin{array}{l}\text { Percentagens de } \\
\text { velhas }(\mathbf{n = 3 0})\end{array}$ & $\begin{array}{l}\text { Percentagens } \\
\text { totais }(n=60)\end{array}$ \\
\hline $\begin{array}{l}\text { Processo natural da vida que devemos } \\
\text { aceitar e nos adaptar }\end{array}$ & 28,0 & 36,7 & 32,3 \\
\hline Apresenta limite físico, cansaço & 21,9 & 16,7 & 19,4 \\
\hline $\begin{array}{l}\text { É uma questão subjetiva (de pensamento, } \\
\text { de cabeça, de estado de espírito) }\end{array}$ & 15,6 & 10,0 & 12,9 \\
\hline Fase boa & 9,4 & 6,7 & 8,1 \\
\hline Experiência, sabedoria & 9,4 & 6,7 & 8,1 \\
\hline Dificil, traz dificuldades & 6,3 & - & 3,2 \\
\hline É uma dádiva de Deus chegar à velhice & 3,1 & 3,3 & 3,2 \\
\hline $\begin{array}{l}\text { É boa quando tem saúde e ruim quando } \\
\text { fica doente }\end{array}$ & - & 6,7 & 3,2 \\
\hline Liberdade & - & 3,3 & 1,6 \\
\hline $\begin{array}{l}\text { Fase em que passa a depender de outras } \\
\text { pessoas }\end{array}$ & - & 3,3 & 1,6 \\
\hline Solidão & - & 3,3 & 1,6 \\
\hline É não ter sonhos/projetos de vida & - & 3,3 & 1,6 \\
\hline Não sabe & 6,3 & - & 3,2 \\
\hline Total de respostas & $f=32$ & $\mathrm{f}=30$ & $f=62$ \\
\hline
\end{tabular}

* Permite respostas múltiplas. Fonte: Autores.

As categorias que emergiram sobre a velhice segundo as pessoas idosas (homens e mulheres) foram: (1) Processo natural da vida que devemos aceitar e nos adaptar; (2) Apresenta limite físico, cansaço; (3) É uma questão subjetiva (de pensamento, de cabeça, de estado de espírito); (4) Fase boa; (5) Experiência, sabedoria; (6) Difícil, traz dificuldades; (7) É uma dádiva de Deus chegar à velhice; (8) É boa quando tem saúde e ruim quando fica doente; (9) Liberdade; (10) Fase em que passa a depender de outras pessoas; (11) Solidão; (12) É não ter sonhos/projetos de vida; e (13) Não sabe.

As categorias que tiveram a maior expressividade entre os conteúdos representacionais sobre a velhice nas percentagens totais, somando 64,6\%, foram: (1) Processo natural da vida que devemos aceitar e nos adaptar; (2) Apresenta limite físico, cansaço; (3) É uma questão subjetiva (de pensamento, de cabeça, de estado de espírito).

A categoria processo natural da vida que devemos aceitar e nos adaptar tem como exemplo de fala: "Olha, velhice pra mim é o passo inevitável da vida. É um passo inevitável da vida" (M06, 71 anos). Percebemos aqui, um conhecimento sobre a velhice como fase de desenvolvimento numa perspectiva tanto biológica (processo natural da vida), quanto psicossocial (devemos aceitar e nos adaptar), constituindo a velhice como processo biológico/social, que requer adaptações por parte das pessoas idosas. A ideia de adaptação revela um viés explicativo evolucionista. Brito et al. (2018, p. 9), comparando as representações sociais da velhice e do cuidado no Brasil e na Itália segundo pessoas idosas, identificaram que, em ambos os países, "a velhice é apontada como uma fase natural da vida, que deve ser aceita e assumida", todavia, entre os italianos o estilo de vida que as pessoas adotam no decorrer do processo de envelhecimento faz parte dessa fase.

Por sua vez, a categoria apresenta limite físico, cansaço pode ser ilustrada com as seguintes falas: "É terrível, porque a gente sente que vai perdendo a vitalidade. Se bem que eu pessoalmente não perdi a minha vitalidade [...]” (M13, 84 anos); “O 
que eu considero mais chato na velhice é o peso do corpo. A gente vai ficando mais pesado, mais lento, vai pensando, também, mais devagar. É uma das coisas que faz com que a gente se sinta velha. A gente não tem mais a mesma mobilidade física que tinha antes, de levantar, deitar, fazer exercício e dançar, essas coisas. A gente vai perdendo essa mobilidade, os joelhos vão ficando doendo, as pernas doem, então são essas coisinhas que acontecem com a gente e faz que a agente esteja assim, cutucando a gente, isso aí é a idade" (F10, 64 anos). Depreendemos das falas que as pessoas idosas compreendem existir limitações em relação à velhice, e estas assumem um caráter físico, relativo aos problemas de mobilidade/pensamento que experimentam, fazendo-os compreender que não possuem o mesmo condicionamento físico/mental das fases anteriores da vida. Melo et al. (2020), investigando quais as representações sociais sobre ser envelhecida e ser idosa para pessoas idosas, identificou em relação à existência de limitações que o surgimento destas são pensadas como indesejáveis e desfavoráveis, identificando a coerência desta representação vinculada à sociedade capitalista.

Já a categoria é uma questão subjetiva (de pensamento, de cabeça, de estado de espírito) pode ser assim exemplificada: "Velhice, para mim, é quando a pessoa se acha velha, se acha inútil. A velhice, para mim, está na mente e não no corpo físico, porque, se a mente é nova, não envelhece, o corpo físico também não" (M02, 60 anos). Identificamos aqui uma compreensão subjetiva da velhice, visto que, o que está em questão para o reconhecimento desta reside na interpretação que se faz de si mesmo, isto é, a autoimagem/autopercepção da pessoa idosa. Faz-se necessário dar-se conta/ver-se/interpretar-se como quem vivencia a velhice num dado momento da vida.

Tabela 2 - O envelhecer na perspectiva de idosos. Região Metropolitana de Salvador/Bahia, 2018 e 2019.

\begin{tabular}{|c|c|c|c|}
\hline Envelhecer segundo idosos* & $\begin{array}{l}\text { Percentagens de velhos } \\
\qquad(\mathbf{n}=30)\end{array}$ & $\begin{array}{l}\text { Percentagens de velhas } \\
\qquad(\mathbf{n}=\mathbf{3 0})\end{array}$ & $\begin{array}{l}\text { Percentagens } \\
\text { totais }(n=60)\end{array}$ \\
\hline $\begin{array}{l}\text { Aceitar a finitude (limites } e \\
\text { mudanças) }\end{array}$ & 16,1 & 40,0 & 27,9 \\
\hline Ter sabedoria, experiência & 16,1 & 16,7 & 16,4 \\
\hline É o tempo passar, viver bastante & 19,4 & 3,3 & 11,5 \\
\hline $\begin{array}{l}\text { Perder a vitalidade, ficar cansado } \\
\text { ou doente }\end{array}$ & 6,5 & 13,3 & 9,8 \\
\hline Viver cada momento e refletir & 12,9 & 6,7 & 9,8 \\
\hline $\begin{array}{l}\text { Passar a depender de outras } \\
\text { pessoas }\end{array}$ & 3,2 & 6,7 & 4,9 \\
\hline $\begin{array}{l}\text { Manter as preocupações da vida } \\
\text { como alimentação e saúde }\end{array}$ & 6,5 & 3,3 & 4,9 \\
\hline $\begin{array}{l}\text { Diminuir atividades fora de casa, } \\
\text { ficar mais em casa }\end{array}$ & 3,2 & 3,3 & 3,3 \\
\hline $\begin{array}{l}\text { É uma questão subjetiva, de } \\
\text { cabeça }\end{array}$ & 6,5 & - & 3,3 \\
\hline $\begin{array}{l}\text { Ir ficando menos bela fisicamente } \\
\text { (cabelo e sobrancelhas mais ralos) }\end{array}$ & - & 6,7 & 3,3 \\
\hline É perder a vontade de viver & 3,2 & - & 1,6 \\
\hline Não sabe & 6,5 & - & 3,3 \\
\hline Total de respostas & $\mathrm{f}=31$ & $\mathrm{f}=30$ & $f=61$ \\
\hline
\end{tabular}

* Permite respostas múltiplas. Fonte: Autores. 
As categorias que emergiram sobre envelhecer segundo as pessoas idosas (homens e mulheres) foram: (1) Aceitar a finitude (limites e mudanças); (2) Ter sabedoria, experiência; (3) É o tempo passar, viver bastante; (4) Perder a vitalidade, ficar cansado ou doente; (5) Viver cada momento e refletir; (6) Passar a depender de outras pessoas; (7) Manter as preocupações da vida como alimentação e saúde; (8) Diminuir atividades fora de casa, ficar mais em casa; (9) É uma questão subjetiva, de cabeça; (10) Ir ficando menos bela fisicamente (cabelo e sobrancelhas mais ralos); (11) É perder a vontade de viver; e (12) Não sabe.

As categorias que tiveram a maior expressividade entre os conteúdos representacionais sobre envelhecer nas percentagens totais, somando 55,8\%, foram: (1) Aceitar a finitude (limites e mudanças); (2) Ter sabedoria, experiência; (3) É o tempo passar, viver bastante.

A categoria aceitar a finitude (limites e mudanças) pode ser ilustrada assim: "É saber que vai morrer, você não tem saída. Ou você aceita que vai morrer e vive cada dia na certeza que pode ser o último ou você envelhece querendo ser novo [...]" (M05, 74 anos). A finitude como representação do envelhecer parece lançar o olhar das pessoas idosas não para a trajetória/processo de envelhecer, mas para um ponto futuro num tempo/momento indefinido, em que o fim da vida irá acontecer de maneira inevitável. As limitações/mudanças parecem ser indicadores para as pessoas idosas do prenúncio da finitude e que a atitude delas deverá ser a de aceitação desta. Oliveira e Anderson (2020), pesquisando a percepção social da morte, da finitude e do envelhecimento a partir das narrativas de idosos em instituição de saúde, identificaram que os idosos participantes não demonstraram temor quando o assunto era morte, indicando não ter medo dela ou ter interesse em falar sobre ela.

A categoria ter sabedoria/experiência pode ser assim exemplificada: "Ganhar experiência, saber ser mais sedutor, saber ser mais conquistador, saber solucionar os problemas com maior facilidade, enfim, é a experiência” (M08, 76 anos). A sabedoria/experiência como representação do envelhecer se apresenta como uma avaliação positiva do processo de envelhecer, pois este seria responsável pela aquisição desses atributos. Essa avaliação pode ser considerada valiosa para as relações interpessoais das pessoas idosas, que conseguem lançar mão desses atributos para interagir, dialogar, escutar, aconselhar, empreender trocas subjetivas e objetivas diversas etc. Castro et al. (2020), comparando as representações sociais do envelhecimento segundo idosos participantes e não participantes de grupos de convivência, identificaram que, em relação à sabedoria, ela favoreceria que oportunidades possam ser identificadas, que antigos projetos fossem retomados e a troca intergeracional pudesse ser facilitada.

A categoria é o tempo passar, viver bastante tem como exemplo a fala: "O que é envelhecer? É passar os anos, pouco a pouco, chegando a uma idade mais avançada, mas mantendo, e isso é muito importante, as faculdades em geral intactas" (M16, 76 anos). A ideia de o tempo passar, viver bastante como representação do envelhecer, é o contrário da categoria aceitar a finitude (limites e mudanças), visto que, aqui, o conhecimento em questão é o processo/trajetória de envelhecer mediado pelo tempo, isto é, a compreensão de que é o tempo vivido - cronológico -, somado à experiência de viver, que caracteriza o envelhecer. Castro et al. (2020), comparando as representações sociais do envelhecimento segundo idosos participantes e não participantes de grupos de convivência, identificaram que a passagem do tempo foi representada pela relação entre vida longa e envelhecimento, isto é, trata-se de viver muito, sendo que os idosos que frequentam o grupo possuem representações mais positivas do que aqueles que não frequentam. 
Research, Society and Development, v. 10, n. 16, e339101623709, 2021

(CC BY 4.0) | ISSN 2525-3409 | DOI: http://dx.doi.org/10.33448/rsd-v10i16.23709

Tabela 3 - Ser velho(a) na perspectiva de idosos. Região Metropolitana de Salvador/Bahia, 2018 e 2019.

\begin{tabular}{|c|c|c|c|}
\hline Ser velho(a) segundo idosos* & $\begin{array}{l}\text { Percentagens de velhos } \\
\qquad(n=30)\end{array}$ & $\begin{array}{l}\text { Percentagens de velhas } \\
\qquad(\mathbf{n}=30)\end{array}$ & $\begin{array}{l}\text { Percentagens } \\
\text { totais }(n=60)\end{array}$ \\
\hline $\begin{array}{l}\text { É o tempo da vida ter passado e } \\
\text { ter mais limitações }\end{array}$ & 12,9 & 40,7 & 27,0 \\
\hline Ter experiência de vida, sabedoria & 22,6 & 12,5 & 17,4 \\
\hline $\begin{array}{l}\text { É quem acha que não tem que } \\
\text { aprender ou fazer mais nada, } \\
\text { perder o otimismo }\end{array}$ & 6,5 & 9,4 & 7,9 \\
\hline $\begin{array}{l}\text { Manter a cabeça boa, mas o físico } \\
\text { com limitações }\end{array}$ & 6,5 & 6,3 & 6,3 \\
\hline Ficar mais sozinho & 3,2 & 9,4 & 6,3 \\
\hline Não ter mais utilidade & 6,5 & - & 3,2 \\
\hline $\begin{array}{l}\text { É ser exemplo de vida para as } \\
\text { pessoas }\end{array}$ & 3,2 & - & 1,6 \\
\hline Viver bastante & 3,2 & - & 1,6 \\
\hline $\begin{array}{l}\text { Tempo de relembrar momentos } \\
\text { bons e ruins }\end{array}$ & 3,2 & - & 1,6 \\
\hline $\begin{array}{l}\text { Momento de colher o que plantou } \\
\text { ao longo da vida }\end{array}$ & 3,2 & - & 1,6 \\
\hline É perder a vontade de viver & 3,2 & - & 1,6 \\
\hline $\begin{array}{l}\text { É como se uma chama fosse se } \\
\text { apagando }\end{array}$ & - & 3,1 & 1,6 \\
\hline É ter vontade própria & - & 3,1 & 1,6 \\
\hline Processo de transformação & - & 3,1 & 1,6 \\
\hline É ter consciência da finitude & 3,2 & - & 1,6 \\
\hline $\begin{array}{l}\text { Para muitas coisas, já ter vivido } \\
\text { bastante, para outras, começar a } \\
\text { viver }\end{array}$ & - & 3,1 & 1,6 \\
\hline É não querer mudar, ser inflexível & - & 3,1 & 1,6 \\
\hline Existem gradações na velhice & 3,2 & - & 1,6 \\
\hline Algo a ser evitado & - & 3,1 & 1,6 \\
\hline Passar a depender dos outros & - & 3,1 & 1,6 \\
\hline É uma dádiva divina (bênção) & 3,2 & - & 1,6 \\
\hline O outro te reconhecer como velho & 3,2 & - & 1,6 \\
\hline É ser desrespeitado & 3,2 & - & 1,6 \\
\hline Não sabe & 9,7 & - & 4,7 \\
\hline Total de respostas & $\mathrm{f}=31$ & $f=32$ & $f=63$ \\
\hline
\end{tabular}

* Permite respostas múltiplas. Fonte: Autores.

As categorias que emergiram sobre ser velho(a) segundo as pessoas idosas (homens e mulheres) foram: (1) É o tempo 
da vida ter passado e ter mais limitações; (2) Ter experiência de vida, sabedoria; (3) É quem acha que não tem que aprender ou fazer mais nada, perder o otimismo; (4) Manter a cabeça boa, mas o físico com limitações; (5) Ficar mais sozinho; (6) Não ter mais utilidade; (7) É ser exemplo de vida para as pessoas; (8) Viver bastante; (9) Tempo de relembrar momentos bons e ruins; (10) Momento de colher o que plantou ao longo da vida; (11) É perder a vontade de viver; (12) É como se uma chama fosse se apagando; (13) É ter vontade própria; (14) Processo de transformação; (15) É ter consciência da finitude; (16) Para muitas coisas, já ter vivido bastante, para outras, começar a viver; (17) É não querer mudar, ser inflexível; (18) Existem gradações na velhice; (19) Algo a ser evitado; (20) Passar a depender dos outros; (21) É uma dádiva divina (bênção); (22) O outro te reconhecer como velho; (23) É ser desrespeitado; e (24) Não sabe.

As categorias que tiveram a maior expressividade entre os conteúdos representacionais sobre ser velho nas percentagens totais, somando 52,3\%, foram: (1) É o tempo da vida ter passado e ter mais limitações; (2) Ter experiência de vida, sabedoria; (3) É quem acha que não tem que aprender ou fazer mais nada, perder o otimismo.

A categoria é o tempo da vida ter passado e ter mais limitações tem como exemplo: "Ser velho é se encontrar com limitações físicas e mentais" (M18, 64 anos). Identificamos aqui, a compreensão das pessoas idosas de que a passagem do tempo oferece limitações - físicas e mentais, visto que tempo e limitações se associam para estas. Ferreira et al. (2017, p. 845), investigando as representações sociais da qualidade de vida para idosos, identificaram que "a fragilidade de saúde e as incapacidades impostas pelo envelhecimento tendem a enfraquecer a interação social e a participação comunitária dos idosos, com riscos de isolamento social e limitações no estilo de vida".

A categoria ter experiência de vida/sabedoria pode ser assim ilustrada: "Bom, ser velho é você conviver bem com a faixa etária que você atingiu. É você colher frutos disso. É você usar sua experiência acumulada para viver melhor esses dias" (M06, 71 anos). Percebemos aqui, um conhecimento sobre ser velho orientado pela compreensão da aquisição dos atributos experiência de vida/sabedoria indicados na categoria. Esses atributos podem favorecer a convivência e as interações sociais das pessoas idosas que as utilizam no cotidiano.

A categoria é quem acha que não tem que aprender ou fazer mais nada, perder o otimismo é assim exemplificada: "Envelhecer é o que vai acontecer de verdade com todo mundo. Agora, ser velho é aquela cabeça assim de que acha que não pode fazer mais nada. Não tem que aprender mais nada" (F3, 73 anos). Depreendemos das falas que as pessoas idosas compreendem o ser velho como uma fase da vida de apatia (quem acha que não tem que aprender ou fazer mais nada), na qual se observa uma atitude negativa (perder o otimismo). Oliveira e Anderson (2020, p. 6), investigando a percepção social da morte, da finitude e do envelhecimento nas narrativas de idosos numa instituição de saúde, identificaram que "os idosos associaram ficar velho/a à inutilidade, à falta de atividades ou falta de vontade/disposição para atividades cotidianas ou de trabalho e à dependência de outras pessoas para atividades de vida diária".

Por fim, destacamos que, ante a questão: “O(A) senhor(a) se sente velho(a)?”, $83 \%$ dos homens afirmaram que não, $10 \%$ deles sentem-se velhos e $7 \%$ para algumas coisas sentem-se velhos e para outras, não. Por seu lado, $80 \%$ das mulheres afirmaram que não; $17 \%$ consideram que para algumas coisas sentem-se velhas e para outras, não; e somente $3 \%$ delas sentemse velhas. Ou seja, a grande maioria dos participantes não se reconhece enquanto velho(a). O termo "velho" está tão carregado de preconceitos, discriminações, estigmas que as pessoas idosas, pelo demérito social, em geral não assumem essa identidade.

\section{Considerações Finais}

O objetivo deste estudo foi alcançado, visto que, analisamos as representações sociais sobre a velhice, o envelhecer e o ser velho, segundo homens e mulheres idosos, destacando as categorias que apresentaram maior expressividade no corpo dos conteúdos representacionais nos três objetos pesquisados (velhice, envelhecer e ser velho). Identificamos que se tratam de representações sociais distintas, ainda que os termos utilizados sejam, aparentemente, muito parecidos: a velhice foi 
representada como processo natural de vida; limitação física/cansaço; e questão subjetiva; o envelhecer teve sua representação associada à aceitar finitude com limites e mudanças; ter sabedoria/experiência; e tempo passar/viver bastante; e o ser velho teve como representação social tempo de vida ter passado/ter mais limitações; ter experiência de vida/sabedoria; e achar que não tem que aprender ou fazer mais nada/perder otimismo.

A identidade social de ser idoso, plasmada nos termos velhice, envelhecer e ser velho revelaram conhecimentos socialmente elaborados e partilhados entre os participantes da pesquisa relacionados às limitações físicas e mentais, ao tempo cronológico, à sapiência, ao desenvolvimento humano como processo, ao fim da vida e às experiências objetivas e subjetivas. Além disso, no geral, os idosos não se reconhecem como velhos.

Levando em consideração que a velhice é uma fase do desenvolvimento humano que cada vez mais pessoas conseguem experienciar, devido ao aumento da expectativa de vida e ao maior reconhecimento/valorização social das pessoas idosas, faz-se necessário compreender, de maneira teórica-metodológica diversificada, as nuances da velhice em suas múltiplas manifestações no cotidiano por meio de ulteriores trabalhos de pesquisa. A teoria das representações sociais favorece a compreensão psicossocial desta fase da vida, permitindo elucidar os conhecimentos presentes no mundo social.

\section{Referências}

Araújo, L. F. de, Carvalho, V. A. M. de L. (2005). Aspectos sócio-históricos e psicológicos da velhice. Mneme. Revista de Humanidades, UFRN, 06 (13), 228236. Recuperado em maio, 2018, de https://periodicos.ufrn.br/mneme/article/view/278

Brito, A. M. M., Belloni, E., Castro, A., Camargo, B. V. Giacomozzi, A. I. (2018). Representações sociais do cuidado e da velhice no Brasil e Itália. Psicologia: Teoria e Pesquisa, 34, 1-11. https://doi.org/10.1590/0102.3772e3455

Castro, J. L. C, Passos, A. L. V., Araújo, L. F., \& Santos, J. V. O. (2020). Análise psicossocial do envelhecimento entre idosos: as suas representações sociais. Actualidades en Psicología, 34(128), 1-15. https://dx.doi.org/10.15517/ap.v34i128.35246

Castro, J. L. C., Araújo, L. F. de, Medeiros, E. D. de, \& Pedroso, J. S. (2021). Representações sociais do envelhecimento e qualidade de vida na velhice ribeirinha. Revista de Psicologia (PUCP), 39(1), 85-113. https://dx.doi.org/10.18800/psico.202101.004

Dias, C. M. de S. B. (2013). Velhice: vulnerabilidades e possibilidades. In: Moreira, L. V. C. (Org.). Psicologia, família e direito: Interfaces e conexões (pp. 259-274). Curitiba: Juruá.

Ferreira, M. C. G., Tura L. F. R., Silva, R. C., Ferreira, M. A. (2017). Representações sociais de idosos sobre qualidade de vida. Revista Brasileira de Enfermagem, 70(4), 840-847. https://doi.org/10.1590/0034-7167-2017-0097

Figueiredo, A. H. (Org.) (2016). Brasil: Uma visão geográfica e ambiental no início do século XXI. Ministério do Planejamento, Desenvolvimento e Gestão Instituto Brasileiro de Geografia e Estatística - IBGE. Rio de Janeiro: Diretoria de Geociências, Coordenação de Geografia.

Góis, E. C. P. de, Santos, J. V. O., \& Araújo, L. F. de. (2020). Representações Sociais sobre a Velhice Masculina: Abordagens de Homens Idosos Participantes de Grupo de Convivência. Revista Subjetividades, 20(Esp1), 1-9. https://doi.org/10.5020/23590777.rs.v20iEsp1.e9140

Instituto Brasileiro de Geografia e Estatística - IBGE (2016). Síntese de Indicadores Sociais. Uma análise das condições de vida da população brasileira.

Diretoria de Pesquisas. Estudos e Pesquisas. Informação Demográfica e Socioeconômica, n. 36. Rio de Janeiro: Coordenação de População e Indicadores Sociais.

Jodelet, D. (2001). Representações sociais: um domínio em expansão. In D. Jodelet (Org.), As representações sociais (pp. 17-44). Rio de Janeiro: EdUERJ.

Melo, L., Arreguy-Sena, C., Gomes, A., Parreira, P., Pinto, P., \& Rocha, J. (2020). Representações sociais elaboradas por pessoas idosas sobre ser idoso ou envelhecido: abordagens estrutural e processual. Revista de Enfermagem da UFSM, 10, 1-20. https://doi.org/10.5902/2179769238464

Moscovici, S. (2012). A psicanálise, sua imagem e seu público. Petrópolis: Vozes.

Moura, E., Delgado, F., \& Mármora, C. (2019). Representações sociais da satisfação com a vida de idosos aposentados. Revista Hospital Universitário Pedro Ernesto, 17(2), 7-15. https://doi.org/10.12957/rhupe.2018.40806

Nascimento, M. C., \& Calsa, G. C. (2017). Velhice e juventude: revisão da produção acadêmica brasileira acerca de suas representações sociais (2005-2015). Educação e Formação, 2(5), 131-143. https://doi.org/10.25053/edufor.v2i5.1956

Oliveira, D. C. (2017). Análise de conteúdo temático-categorial: uma técnica maior nas pesquisas qualitativas. In M. R. Lacerda \& R. G. S. Costenaro (Orgs.), Metodologias da pesquisa para a enfermagem e saúde: da teoria à prática (pp. 481-511). Porto Alegre: Moriá.

Oliveira, P. I. D. de., \& Anderson, M. I. P. (2020). Envelhecimento, finitude e morte: narrativas de idosos de uma unidade básica de saúde. Revista Brasileira de Medicina de Família e Comunidade, 15(42), 1-11. https://doi.org/10.5712/rbmfc15(42)2195

Sá, C. P. (1996). Representações sociais: teoria do núcleo central. Temas em Psicologia, 3. 19-33. 
Research, Society and Development, v. 10, n. 16, e339101623709, 2021

(CC BY 4.0) | ISSN 2525-3409 | DOI: http://dx.doi.org/10.33448/rsd-v10i16.23709

Sardinha, M. T. M. U., Sá, S. P. C., Ferreira, J. B. dos S., Lindolpho, M. da C., Domingos, A. M., \& Melo, V. L. (2020). Qualidade de vida de idosos com doenças crônicas e suas representações sociais. Research, Society and Development, 9(9), 1-19. Recuperado em outubro, 2021, de https://doi.org/10.33448/rsdv9i9.6470

Schaie, K. W., Willis, S. L. (2000). A stage theory model of adult cognitive development revisited. In: Rubinstein, R., Moss, M., Kleban, M. H. (Eds.). The many dimensions of aging (pp 1-11). Springer Publishing Company.

Silva, H. G., Nogueira J. M., Santos Junior E. B., Coutinho, D. T. R., Freitas, M. C. (2020). Representações sociais de mulheres idosas sobre o envelhecimento. Revista de Enfermagem do Centro Oeste Mineiro, 10, 1-8. http://doi.org/10.19175/recom.v10i0.3821

Tomé, A. M., \& Formiga, N. S. (2020). Teorias e perspectivas sobre o envelhecimento: conceitos e reflexões. Research, Society and Development, 9(7), 1-28. https://doi.org/10.33448/rsd-v9i7.4589 